\title{
Composição do sangue e do leite em ovinos leiteiros do sul do Brasil: variações na gestação e na lactação
}

\author{
Blood and milk composition in dairy ewes from southern Brazil: variations during \\ pregnancy and lactation

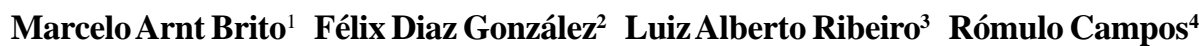 \\ Luciana Lacerda $^{5}$ Patrícia Rick Barbosa ${ }^{6}$ Guiomar Bergmann ${ }^{7}$
}

\section{RESUMO}

A ovinocultura de leite tem avançado no Rio Grande do Sul nos últimos anos, sem o conhecimento das variações nos parâmetros metabólicos e de composição do leite que possa servir de apoio à pesquisa e à clínica. Este trabalho teve por objetivo estudar a variação dos perfis metabólico e hematológico e da composição do leite em ovinos leiteiros da raça Lacaune criados em regime de confinamento na Serra Gaúcha. O trabalho foi realizado no município de Bento Gonçalves (região serrana do RS). Foram coletadas amostras de sangue de 14 animais por venipunção jugular para a realização de hemograma e do perfil bioquímico, em cada uma das seguintes categorias: ovelhas vazias; aos 60, 90 e 120 dias de gestação e aos 7, 30, 60 e 140 dias de lactação. Durante os mesmos períodos da lactação, foram coletadas amostras para a determinação dos componentes físico-químicos do leite. A acidez Dornic e o teor de proteína e gordura do leite foram diferentes dos citados em outros países. O perfil metabólico apresentou maiores variações com relação à média no final da gestação e no início da lactação. A uréia mostrou diferença $(P<0,05)$ entre a gestação e a lactação. Os valores de glicose e fructosamina diminuíram e os de betahidroxibutirato aumentaram $(P<0,05)$ no final da gestação. Com o avanço da lactação, houve diminuição da glicose $e$ aumento do colesterol $(P<0,05)$. O fósforo apresentou diminuição 30 dias após o parto $(P<0,05)$. Os parâmetros hematológicos não mostraram diferença nos períodos fisiológicos estudados, com exceção dos neutrófilos segmentados, que aumentaram com o avanço da gestação. Os dados encontrados servem como referência para estudos sobre nutrição, metabolismo e qualidade do leite em ovelhas leiteiras.
Palavras-chave: ovelhas leiteiras, composição do leite, perfil metabólico, hematologia.

\section{ABSTRACT}

Dairy sheep industry has increased intensively in southern Brazil, however, without the corresponding knowledge of variations on metabolic and hematological parameters and on milk composition, with application in research and clinical activities. This work was carried out on Lacaune sheep, intensively grazed in the county of Bento Gonçalves (RS), in southern Brazil. Blood samples were collected from the jugular vein for metabolic profiles and hematology. Samples were taken randomly from 14 sheep in each of the following periods: nonpregnant ewes; at 60, 90 and 120 of pregnancy and at 7 , 30, 60 and 140 days of lactation. During the lactation period, milk samples were also taken to assay the physico-chemical composition. Milk acidity, protein and fat levels were different from reference levels in another countries. The most relevant changes on metabolic profile were noticed at the end of gestation and at the beginning of lactation. Urea values showed variation $(P<0.05)$ during the gestation and lactation periods. The levels of glucose and fructosamine decreased and the BHB increased significantly at the end of gestation period $(P<0.05)$. During the lactation period glucose level lowered and cholesterol level increased significantly $(P<0.05)$. Phosphorus level lowered, specially at 30 days post parturition $(P<0.05)$. Hematologic parameters did not show variation during the physiologic periods studied. An exception was the segmented neutrophils that increased with the advance of the gestation $(P<0.05)$. The data presented here may help for further nutrition and metabolic studies on dairy sheep and milk quality.

Key words: dairy ewes, milk composition, metabolic profile, hematology.

${ }^{1}$ Caminhos de Pedra, Bento Gonçalves, RS, Brasil.

${ }^{2}$ Laboratório de Análises Clínicas Veterinárias, Universidade Federal do Rio Grande do Sul (UFRGS), Porto Alegre, RS, Brasil. Email: felixgon@ufrgs.br. Autor para correspondência.

${ }^{3}$ Departamento de Medicina Animal, Faculdade de Veterinária, UFRGS, Porto Alegre, RS, Brasil.

${ }^{4}$ Facultad de Ciencias Agropecuarias, Universidad Nacional de Colombia, Bogotá, Colômbia.

${ }^{5}$ Programa de Pós-graduação em Ciências Veterinárias, UFRGS, Porto Alegre, RS, Brasil.

${ }^{6}$ Faculdade de Veterinária, UFRGS, Porto Alegre, RS, Brasil.

${ }^{7}$ Setor de Inspeção e Tecnologia de Produtos de Origem Animal, Faculdade de Veterinária, UFRGS, Porto Alegre, RS, Brasil. 


\section{INTRODUÇÃO}

Os primeiros ovinos com aptidão leiteira foram trazidos ao Brasil em 1992. A raça introduzida foi a Lacaune, da França, que atualmente está bem adaptada às condições de clima e alimentação do sul do Brasil. Uma fêmea Lacaune pode produzir 4,5 litros de leite/dia no pico da lactação, que ocorre ao redor dos 30 dias pós-parto, durando o período de lactação aproximadamente 150 dias. O leite de ovelha difere das demais espécies especialmente pela riqueza dos constituintes, existindo diferenças entre rebanhos (ASSENAT, 1991). Muitos fatores contribuem nas variações da composição e na qualidade do leite de ovelhas, entre os quais estão o ambiente, a raça, a idade, o estágio da lactação, o nível nutricional e as técnicas de ordenha (PEETERS et al., 1992; BENCINI \& PULINA, 1997). Os componentes do leite que mais variam em função da alimentação do animal são a gordura e a proteína, que respondem por até $50 \%$ dessas variações (FREDEEN, 1996).

O perfil metabólico em ruminantes pode ser usado para monitorar a adaptação metabólica e diagnosticar desequilíbrios metabólico-nutricionais. RUSSEL (1991) afirma que o método mais rápido de avaliar o equilíbrio nutricional de ovinos, em períodos críticos, é a determinação de alguns metabólitos na circulação. Outra forma de avaliar a resposta do organismo frente aos processos fisiológicos de cada fase do ciclo reprodutivo em ovinos é o acompanhamento do hemograma (KRAJNICAKOVA et al., 1995). A ovinocultura demanda a necessidade de novos métodos de avaliação metabólico-nutricional em virtude da maior casuística de doenças metabólicas. Nesse sentido, o hemograma e o perfil metabólico podem servir de auxílio no diagnóstico e na prevenção destas doenças, principalmente em animais de alta produção (GONZÁLEZ et al., 2000). A contagem de células somáticas e o “California Mastitis Test” (CMT) são importantes ferramentas para o diagnóstico de mastites, diminuindo perdas em produção antes que sejam percebidas em níveis econômicos.

O objetivo deste trabalho foi estudar as variações da composição do sangue (hemograma e perfil bioquímico) durante a gestação e a lactação e as variações dos componentes físico-químicos do leite ao longo da lactação, em ovelhas Lacaune criadas na região serrana do Rio Grande do Sul (RS).

\section{MATERIAL E MÉTODOS}

O trabalho foi realizado em um rebanho de ovelhas leiteiras da raça Lacaune, no município de Bento
Gonçalves, região serrana do RS, cuja altitude média é de $600 \mathrm{~m}$ acima do nível do mar, com localização geográfica $29^{\circ} 07^{\prime} 16^{\prime \prime}$ de latitude sul e $51^{\circ} 26^{\prime} 44^{\prime \prime}$ de longitude oeste. A temperatura anual média é de $16,5^{\circ} \mathrm{C}$ e a precipitação é de $1823 \mathrm{~mm}^{2} \mathrm{ano}^{-1}$. O rebanho estava formado por 450 ovelhas Lacaune puras e Lacaune $\mathrm{x}$ Texel. O sistema de criação foi o de confinamento em galpão, tendo casca de arroz como cama e janelas nas paredes laterais para circulação de ar. A alimentação, fornecida nos cochos duas vezes ao dia, foi de silagem de milho e pasto verde (tifton, aveia e azevém) ou feno. Também era fornecido concentrado contendo farelo de soja, casca de soja, grão de milho e premix mineralvitamínico para ovinos, contendo 19,34\% de PB e $74,44 \%$ de NDT.

Foram selecionadas 100 ovelhas entre a segunda e a quarta lactação com grau de sangue acima de 7/8 Lacaune e realizado exame clínico desses animais para conferir seu estado sanitário. Os animais eram ordenhados duas vezes ao dia com uso de ordenhadeira mecânica própria para ovinos. Na época de reprodução, as ovelhas tiveram o estro sincronizado com pesários intravaginais contendo medroxiprogesterona (12 dias) e foram inseminadas com sêmen fresco, 48 horas após a retirada dos pesários. Repasse com carneiros foi feito durante 30 dias após a inseminação. O diagnóstico de gestação foi feito por ultra-sonografia 30 dias após o repasse (Vetscan 2 equipado com transdutor setorial de 3,5 MHz). Após o diagnóstico de gestação, foram escolhidas ao acaso 14 ovelhas vazias e 14 ovelhas gestantes (60 dias de gestação). A partir desse momento, foram selecionadas ao acaso 14 ovelhas do lote total, nos seguintes períodos: 90 e 120 dias de gestação e 7, 30, 60 e 140 dias de lactação. Desses 14 animais de cada categoria, foram coletadas amostras de sangue por venipunção jugular em tubos vacutainer com EDTA para o hemograma e sem anticoagulante para o perfil metabólico. As coletas de sangue foram realizadas antes da ordenha da manhã e as amostras mantidas em refrigeração até a chegada no laboratório. Em cada período, foi avaliada a condição corporal (escala 1-5).

No hemograma, as contagens totais de eritrócitos e leucócitos foram feitas pela técnica de microdiluição e contagem em câmara de Neubauer, o hematócrito determinado por microcentrifugação e a hemoglobina dosada pela técnica colorimétrica do cianeto de potássio ${ }^{a}$. A partir do esfregaço sangüíneo corado com o corante de Wright, foi realizada a contagem diferencial de leucócitos.

As amostras de sangue sem anticoagulante foram centrifugadas ( $2500 \mathrm{rpm}$ por $15 \mathrm{~min}$ ), o soro foi retirado e armazenado a $-20^{\circ} \mathrm{C}$ até o momento das 
análises para perfil metabólico, as quais foram realizadas por métodos espectrofotométricos, utilizando kits diagnósticos ${ }^{\mathrm{a}}$. O perfil examinado incluiu os seguintes metabólitos (entre parênteses os métodos): albumina (verde de bromocresol), proteína total (biureto), colesterol (colesterol oxidase), glicose (glicose oxidase), fructosamina (redução do azul de nitroterazólio), uréia (urease), triglicerídeos (enzimático-Trinder), cálcio (púrpura de ftaleína), fósforo inorgânico (molibdato de amônia), magnésio (magon sulfonado) e betahidroxibutirato (UV enzimático ${ }^{\mathrm{b}}$ ).

As amostras de leite foram coletadas durante a ordenha da manhã, resfriadas e mantidas a $4^{\circ} \mathrm{C}$ até a sua análise. Os exames do leite incluíram (entre parênteses os métodos): pH (potenciômetro digital), acidez Dornic (titulação), densidade (termolactodensímetro de Quevene a $15^{\circ} \mathrm{C}$ ), gordura (Gerber), extrato de sólidos totais (EST, fórmula de Fleischmann), extrato de sólidos desengordurados (ESD, diferença EST - gordura). Proteína e lactose foram determinadas por espectrofotometria no infravermelho próximo (NIRS) ${ }^{\mathrm{c}}$ e expressas em porcentagem, e a contagem de células somáticas (CCS) por citometria de fluxo $^{\mathrm{d}}$. Uréia no leite foi determinada pelo método da urease em amostras desproteinizadas. Foi realizado o exame CMT por ocasião das coletas de leite e expressado como percentagem de animais não reagentes.

A análise estatística dos dados foi realizada com o programa Minitab para Windows, onde foram calculadas as médias e o desvio padrão de cada parâmetro e a análise de variância, para conhecer o efeito dos períodos de amostragens sobre as variáveis. As diferenças entre médias foram realizadas pelo teste de Tukey e o nível de significância adotado foi de 0,05.

\section{RESULTADOS E DISCUSSÃO}

A literatura brasileira sobre ovinos leiteiros é reduzida. No presente trabalho, são apresentados dados referentes às variações do hemograma, do perfil bioquímico (metabólico) e da composição de leite de ovelhas Lacaune durante a gestação e a lactação.

A duração média da lactação das ovelhas estudadas foi de 160 dias, com uma produção média de leite de 1,3L ovelha ${ }^{-1} \mathrm{dia}^{-1}$. A tabela 1 mostra os valores das características fisico-químicas do leite das ovelhas nos períodos da lactação. A tabela 2 mostra os valores do perfil metabólico e da condição corporal das ovelhas vazias e em diferentes períodos da gestação e da lactação. A tabela 3 apresenta o valores do hemograma observados no grupo de ovelhas vazias e gestantes e durante a lactação.
O pH médio do leite obtido neste estudo $(6,53)$ está próximo do valor descrito por ASSENAT (1991) para ovinos da mesma raça na França $(6,65)$. A acidez Dornic média $\left(25,13 \pm 4,7^{\circ} \mathrm{D}\right)$ foi maior que o intervalo citado pelo mesmo autor para ovinos Lacaune (18-22 D) e próximo do intervalo citado por GONZÁLEZ \& VIZCAYA(1993) de 16-25D D. A acidez Dornic está diretamente relacionada com a concentração do dióxido de carbono, proteína, fosfato e citrato no leite (ASSENAT, 1991) e os resultados aqui obtidos mostram que esse parâmetro aumenta com o progresso da lactação, o que poderia estar relacionado com o aumento da proteína do leite observada no período. A densidade média foi de $1.036 \mathrm{~g} \mathrm{~mL}^{-1}$, situada dentro do intervalo citado por ASSENAT (1991) de 1.034 a $1.038 \mathrm{~g}$ $\mathrm{mL}^{-1}$. A densidade do leite tem relação inversa com a temperatura e o teor de gordura e, no presente trabalho, a densidade diminuiu durante a lactação, coincidindo com o aumento do teor de gordura no mesmo período.

A média de proteína do leite encontrada no presente estudo (4,46\%) foi semelhante à descrita por SCHOLZ (1997). Os valores mostraram avanço progressivo ao longo da lactação, como descreveu LUQUET (1991). O nível da lactose no leite é pouco influenciado por fatores nutricionais, estando relacionado com a produção de leite (FREDEEN, 1996). No presente estudo, o valor médio de lactose foi de $4,76 \%$, que está dentro do intervalo descrito por SCHOLZ (1997) de 4,2 a 5,0\%, porém menor que a média de 5,27\% relatada por KREMER et al. (1996) em ovelhas Corriedale no Uruguai. O maior teor de lactose foi observado aos 30 dias de lactação, coincidindo com o pico de produção.

O teor médio de gordura do leite encontrado foi de 5,79\%, mostrando um gradativo aumento com o progresso da lactação. Os valores são menores que os descritos por LUQUET (1991) em ovinos Lacaune, de $5,97 \%$ no início e de 8,38\% no final da lactação. Os componentes do Extrato Seco Total (EST) somaram em média 16,25\%, valor inferior ao citado por ALVARENGA (2002), que registrou valores entre 18,40 e 19,1\%, porém similar ao descrito por ASSENAT (1991) para ovelhas Lacaune. Em todos esses estudos, foi descrito um aumento de EST ao longo da lactação. O valor médio de Extrato Seco Desengordurado (ESD) deste trabalho foi de $10,43 \%$, menor que os resultados descritos pelos autores mencionados.

Os valores da CCS obtidos neste trabalho foram similares aos encontrados por GONZALO et al. (1994) em ovelhas da raça Churra na Espanha. Segundo o autor, ocorre um aumento fisiológico da CCS no início e no final da lactação. O valor médio da CCS no presente trabalho (171.750 células $\mathrm{mL}^{-1}$ ) é menor que os valores 
Tabela 1 - Características fisico-químicas (média e desvio padrão) do leite de ovelhas da raça Lacaune criadas no RS em diferentes períodos da lactação.

\begin{tabular}{|c|c|c|c|c|}
\hline Parâmetro & 7 dias & 30 dias & 60 dias & 140 dias \\
\hline $\mathrm{N}$ & 14 & 14 & 14 & 14 \\
\hline $\mathrm{pH}$ & $6,54^{\mathrm{a}} \pm 0,28$ & $6,29^{\mathrm{b}} \pm 0,41$ & $6,74^{\mathrm{a}} \pm 0,15$ & $6,56^{\mathrm{a}} \pm 0,12$ \\
\hline Acidez $\left({ }^{\circ} \mathrm{D}\right)$ & $23,60^{\mathrm{b}} \pm 3,54$ & $23,53^{\mathrm{b}} \pm 6,7$ & $24,93^{\mathrm{b}} \pm 3,05$ & $28,46^{\mathrm{a}} \pm 3,24$ \\
\hline Densidade (g/mL) & $1.038^{\mathrm{a}} \pm 2,1$ & $1.035^{\mathrm{b}} \pm 2,2$ & $1.036^{\mathrm{a}} \pm 1,2$ & $1.037^{\mathrm{a}} \pm 1,0$ \\
\hline Proteína (\%) & $4,23^{\mathrm{b}} \pm 0,34$ & $4,27^{\mathrm{b}} \pm 0,35$ & $4,30^{\mathrm{b}} \pm 0,30$ & $5,04^{\mathrm{a}} \pm 0,32$ \\
\hline Lactose (\%) & $4,69^{\mathrm{b}} \pm 0,29$ & $5,04^{\mathrm{a}} \pm 0,17$ & $4,74^{\mathrm{b}} \pm 0,27$ & $4,56^{\mathrm{b}} \pm 0,23$ \\
\hline Gordura (\%) & $4,90^{\mathrm{C}} \pm 0,67$ & $5,99^{\mathrm{b}} \pm 1,34$ & $5,26^{\mathrm{b}, \mathrm{c}} \pm 1,27$ & $7,02^{\mathrm{a}} \pm 1,02$ \\
\hline Uréia (mmol/L) & $9,06 \pm 2,72$ & $9,39 \pm 2,11$ & $9,05 \pm 1,31$ & $7,55 \pm 1,34$ \\
\hline $\mathrm{EST}^{1}(\%)$ & $15,42^{\mathrm{b}} \pm 0,87$ & $16,26^{\mathrm{b}} \pm 1,51$ & $15,54^{\mathrm{b}} \pm 1,43$ & $17,81^{\mathrm{a}} \pm 1,47$ \\
\hline $\mathrm{ESD}^{2}(\%)$ & $10,50^{\mathrm{a}} \pm 0,41$ & $10,21^{\mathrm{b}} \pm 0,34$ & $10,28^{\mathrm{b}} \pm 0,28$ & $10,74^{\mathrm{a}} \pm 0,45$ \\
\hline $\mathrm{CMT}^{3}$ (\% não reagente) & 87,5 & 85,5 & 93,5 & 93,5 \\
\hline $\mathrm{CCS}^{4}(\mathrm{x} 1000 / \mathrm{mL})$ & $231 \pm 427$ & $50 \pm 82$ & $198 \pm 552$ & $207 \pm 370$ \\
\hline
\end{tabular}

Letras diferentes na mesma linha indicam diferença significativa $(\mathrm{P}<0,05)$.

${ }^{1}$ EST: extrato seco total; ${ }^{2}$ ESD: extrato seco desengordurado; ${ }^{3} \mathrm{CMT}$ : California Mastitis Test; ${ }^{4} \mathrm{CCS}$ : contagem de células somáticas.

descritos por PAAPE et al. (2001) e BARILLET et al. (2001). Não houve diferença significativa para os valores de uréia no leite, percentual de ovelhas reagentes para CMT nem para os valores da CCS nos períodos estudados (Tabela 1).

No presente trabalho, é apresentado o perfil metabólico das ovelhas Lacaune durante os períodos de gestação e lactação. Nos indicadores protéicos, não houve variação significativa durante períodos. Em outros países (ALTHAUS et al., 1995; WITTWER, 2000) e no sul do Brasil (RIBEIRO, 2002), relata-se uma redução desses metabólitos com o avanço da gestação ou da lactação em função de balanço nitrogenado negativo. A condição corporal (CC) tem sido utilizada junto com parâmetros do metabolismo energético para avaliar as reservas de gordura. O menor valor de CC foi verificado no início da lactação, quando também foi observado o nível mais alto de beta-hidroxibutirato (BHB), sugerindo consumo das reservas corporais e balanço energético negativo (Tabela 2). Os componentes do metabolismo energético mostraram, como períodos críticos de déficit energético, o final da gestação e o início da lactação, como foi descrito por RIBEIRO (2002). A concentração de glicose mostrou diminuição $(\mathrm{P}<0,05)$ no final da gestação, o que pode estar relacionado com o rápido crescimento fetal nas últimas semanas de gestação (RUSSEL, 1991). A diminuição de glicose no pico da lactação está relacionada com a captação deste metabólito pela glândula mamária para a síntese de lactose. Os níveis de fructosamina mostraram comportamento semelhante aos de glicose nos períodos estudados, evidenciando o déficit energético, situação de risco para a apresentação de toxemia da gestação (KANEKO et al., 1997). A perda da CC durante a gestação e início da lactação explica os maiores valores de BHB encontrados nesses períodos, indicando lipomobilização (TADICH et al., 1994).

A concentração de colesterol manteve-se acima dos valores de referência (KANEKO et al., 1997). O período de lactação caracterizou-se por aumento gradual dos valores de colesterol, sem que exista uma aparente explicação para isto. Não foram verificadas variações nos triglicerídeos durante a gestação e a lactação.

O cálcio não é um bom indicador do estado nutricional do rebanho devido ao rigoroso controle endócrino da calcemia, enquanto que o fósforo e o magnésio refletem melhor o status nutricional mineral (WITTWER, 2000). No presente estudo, os valores plasmáticos de cálcio estiveram sempre abaixo dos valores de referência informados por KANEKO et al. (1997), de 2,87 a 3,20 $\mathrm{mmol} \mathrm{L}^{-1}$, mostrando, entretanto, comportamento semelhante ao descrito por RIBEIRO et al. (2004) em ovelhas do RS. Os valores mais baixos desse mineral foram observados no início e no pico da lactação (30 dias), quando acontece a maior demanda desse mineral. Os níveis de magnésio mantiveram-se dentro do intervalo de referência (KANEKO et al., 1997). No terço final da gestação e aos 30 dias de lactação, a concentração do fósforo ficou próxima do limite inferior para a espécie, indicando maior gasto nesses períodos. 
Tabela 2 - Média e desvio padrão do perfil metabólico e da condição corporal em ovelhas Lacaune vazias e durante a gestação e a lactação.

\begin{tabular}{|c|c|c|c|c|}
\hline Parâmetro & Vazias & 60 dias de gestação & 90 dias de gestação & 120 dias de gestação \\
\hline $\mathrm{N}$ & 14 & 14 & 14 & 14 \\
\hline Condição corporal (1-5) & $3,14 \pm 0,41$ & $3,03 \pm 0,36$ & $3,00 \pm 0,39$ & $2,96 \pm 0,66$ \\
\hline Proteína (g/L) & $78,2 \pm 8,2$ & $73,2 \pm 7,8$ & $69,3 \pm 10,6$ & $64,6 \pm 6,3$ \\
\hline Globulina (g/L) & $40,4 \pm 4,0$ & $36,4 \pm 7,5$ & $34,6 \pm 10,0$ & $30,7 \pm 7,2$ \\
\hline Albumina (g/L) & $37,8 \pm 6,7$ & $36,8 \pm 3,3$ & $34,7 \pm 2,3$ & $33,8 \pm 4,6$ \\
\hline Uréia (mmol/L) & $5,46^{\mathrm{a}} \pm 1,39$ & $3,49^{\mathrm{b}} \pm 1,92$ & $6,14^{a} \pm 3,46$ & $3,48^{\mathrm{b}} \pm 1,82$ \\
\hline ß-OH-butirato (mmol/L) & $0,18^{\mathrm{b}} \pm 0,16$ & $0,17^{\mathrm{b}} \pm 0,17$ & $0,27^{\mathrm{a}, \mathrm{b}} \pm 0,19$ & $0,38^{\mathrm{a}} \pm 0,17$ \\
\hline Glicose (mmol/L) & $2,97^{\mathrm{b}} \pm 0,57$ & $3,10^{\mathrm{a}, \mathrm{b}} \pm 0,66$ & $3,73^{\mathrm{a}} \pm 0,58$ & $2,96^{\mathrm{b}} \pm 0,61$ \\
\hline Colesterol (mmol/L) & $2,78 \pm 0,56$ & $2,31 \pm 0,53$ & $2,02 \pm 0,33$ & $2,20 \pm 0,46$ \\
\hline Fructosamina $(\mathrm{mmol} / \mathrm{L})$ & $1,84^{\mathrm{a}} \pm 0,26$ & $1,78^{\mathrm{a}} \pm 0,21$ & $1,64^{\mathrm{a}} \pm 0,19$ & $1,39^{\mathrm{b}} \pm 0,29$ \\
\hline Triglicerídeos (mg/dL) & $30,7 \pm 10,8$ & $32,2 \pm 9,8$ & $28,7 \pm 10,0$ & $52,2 \pm 16,4$ \\
\hline Cálcio (mmol/L) & $2,75^{\mathrm{a}} \pm 0,24$ & $2,44^{\mathrm{b}} \pm 0,34$ & $2,45^{\mathrm{b}} \pm 0,29$ & $2,45^{\mathrm{b}} \pm 0,29$ \\
\hline Magnésio (mmol/L) & $1,06 \pm 0,18$ & $1,03 \pm 0,08$ & $1,02 \pm 0,09$ & $1,13 \pm 0,20$ \\
\hline Fósforo $(\mathrm{mmol} / \mathrm{L})$ & $2,45 \pm 0,96$ & $2,23 \pm 1,13$ & $1,77 \pm 0,72$ & $1,70 \pm 0,89$ \\
\hline \multirow{2}{*}{ Parâmetro } & \multicolumn{4}{|c|}{ Período da lactação } \\
\hline & 7 dias & 30 dias & 60 dias & 140 dias \\
\hline $\mathrm{N}$ & 14 & 14 & 14 & 14 \\
\hline Condição corporal (1-5) & $2,82^{b} \pm 0,57$ & $2,92^{\mathrm{b}} \pm 0,58$ & $3,17^{\mathrm{a}, \mathrm{b}} \pm 0,42$ & $3,33^{\mathrm{a}} \pm 0,45$ \\
\hline Proteína (g/L) & $70,4 \pm 11,2$ & $64,8 \pm 13,2$ & $69,8 \pm 5,7$ & $71,3 \pm 7,5$ \\
\hline Globulina (g/L) & $35,9 \pm 9,7$ & $30,6 \pm 9,2$ & $35,3 \pm 3,2$ & $34,0 \pm 7,2$ \\
\hline Albumina (g/L) & $34,5 \pm 3,0$ & $34,2 \pm 6,1$ & $34,4 \pm 4,1$ & $37,3 \pm 2,9$ \\
\hline Uréia (mmol/L) & $7,34^{\mathrm{b}} \pm 1,67$ & $10,24^{\mathrm{a}} \pm 2,21$ & $9,90^{\mathrm{a}} \pm 1,41$ & $9,58^{\mathrm{a}, \mathrm{b}} \pm 2,67$ \\
\hline ß-hidroxibutirato (mmol/L) & $0,51 \pm 0,16$ & $0,38 \pm 0,21$ & $0,37 \pm 0,19$ & $0,40 \pm 0,20$ \\
\hline Glicose (mmol/L) & $3,11^{\mathrm{a}} \pm 0,52$ & $2,18^{\mathrm{b}} \pm 0,74$ & $2,68^{\mathrm{a}, \mathrm{b}} \pm 0,48$ & $2,03^{\mathrm{b}} \pm 0,51$ \\
\hline Colesterol (mmol/L) & $1,84^{\mathrm{b}} \pm 0,24$ & $1,84^{\mathrm{b}} \pm 0,78$ & $2,32^{\mathrm{a}, \mathrm{b}} \pm 0,38$ & $2,49^{\mathrm{a}} \pm 0,50$ \\
\hline Fructosamina $(\mathrm{mmol} / \mathrm{L})$ & $1,73 \pm 0,27$ & $1,62 \pm 0,46$ & $1,80 \pm 0,34$ & $1,66 \pm 0,27$ \\
\hline Triglicerídeos (mg/dL) & $31,5 \pm 13,9$ & $34,7 \pm 27,7$ & $41,4 \pm 13,1$ & $33,8 \pm 16,2$ \\
\hline Cálcio (mmol/L) & $2,37 \pm 0,17$ & $2,24 \pm 0,36$ & $2,45 \pm 0,19$ & $2,42 \pm 0,18$ \\
\hline Magnésio (mmol/l) & $1,06^{\mathrm{b}} \pm 0,20$ & $1,16^{\mathrm{a}, \mathrm{b}} \pm 0,17$ & $1,15^{\mathrm{a}, \mathrm{b}} \pm 0,13$ & $1,24^{\mathrm{a}} \pm 0,18$ \\
\hline Fósforo (mmol/L) & $2,14^{\mathrm{a}} \pm 1,26$ & $1,44^{\mathrm{b}} \pm 0,68$ & $1,63^{\mathrm{a}, \mathrm{b}} \pm 0,67$ & $2,01^{\mathrm{a}} \pm 0,77$ \\
\hline
\end{tabular}

Letras diferentes na mesma linha indicam diferença significativa $(\mathrm{P}<0,05)$.

Os componentes do hemograma avaliados neste estudo (Tabela 3) se encontram dentro do intervalo de referência para a espécie ovina (JAIN, 1993). Não foi observada diferença nos constituintes hematológicos entre ovelhas vazias e prenhes. Apesar de não apresentar diferença significativa, o hematócrito diminui com o avanço da gestação, fato semelhante ao relatado por FORTAGNE \& SCHAFER (1989). Dos parâmetros da série leucocitária, apenas os neutrófilos segmentados apresentaram diferença entre os diferentes períodos, aumentando com o avanço da gestação. Esse achado é semelhante ao descrito por
JAIN (1993), JALINEK et al. (1986) e ANOSA \& OGBOGU (1979), autores que consideram esse aumento como fisiológico.

\section{CONCLUSÃO}

O presente trabalho mostra a composição do sangue e do leite de ovelhas leiteiras da raça Lacaune nas condições do Sul do Brasil. O perfil metabólico analisado mostra que as maiores variações dos metabólitos sangüíneos ocorrem nos períodos de final da gestação e início da lactação, que

Ciência Rural, v.36, n.3, mai-jun, 2006. 
Tabela 3 - Média e desvio padrão de parâmetros do hemograma em ovelhas Lacaune vazias e durante a gestação e a lactação.

\begin{tabular}{|c|c|c|c|c|}
\hline Parâmetro & Vazias & 60 dias de gestação & 90 dias de gestação & 120 dias de gestação \\
\hline $\mathrm{N}$ & 14 & 14 & 14 & 14 \\
\hline Hematócrito (\%) & $39,5 \pm 3,7$ & $37,07 \pm 2,92$ & $34,69 \pm 5,87$ & $34,00 \pm 5,15$ \\
\hline Hemoglobina (g/dL) & $13,8 \pm 1,3$ & $12,28 \pm 1,19$ & $11,82 \pm 1,87$ & $12,41 \pm 1,92$ \\
\hline Eritrócitos totais $\left(\mathrm{x} 10^{6} / \mathrm{uL}\right)$ & $13,2 \pm 1,2$ & $12,35 \pm 0,97$ & $11,72 \pm 2,11$ & $11,51 \pm 1,89$ \\
\hline Leucócitos totais (/uL) & $7964 \pm 2752$ & $6636 \pm 1620$ & $6869 \pm 1790$ & $9314 \pm 3240$ \\
\hline Neutrófilos em bastão (/uL) & $0,07 \pm 0,2$ & 0 & 0 & 0 \\
\hline Neutrófilos segmentados (/uL) & $2090^{\mathrm{b}} \pm 1432$ & $1668^{\mathrm{b}} \pm 750$ & $1862^{b} \pm 1201$ & $4234^{\mathrm{a}} \pm 1869$ \\
\hline Eosinófilos (/uL) & $866,7 \pm 975,9$ & $642,8 \pm 722,7$ & $439,5 \pm 433,9$ & $365,2 \pm 348,6$ \\
\hline Basófilos (/uL) & $42,6 \pm 50,4$ & $22,5 \pm 42,3$ & $8,8 \pm 21,8$ & $30,2 \pm 66,3$ \\
\hline Monócitos (/uL) & $261,6 \pm 109,6$ & $174,7 \pm 123,2$ & $143 \pm 88$ & $293,5 \pm 165,6$ \\
\hline Linfócitos (/uL) & $4697 \pm 1249$ & $4127 \pm 1206$ & $3945 \pm 1817$ & $4390 \pm 1813$ \\
\hline \multirow{2}{*}{ Parâmetro } & \multicolumn{4}{|c|}{ Período da lactação } \\
\hline & 7 dias & 30 dias & 60 dias & 140 dias \\
\hline $\mathrm{N}$ & 14 & 14 & 14 & 14 \\
\hline Hematócrito (\%) & $31,84 \pm 4,43$ & $33,50 \pm 4,87$ & $32,07 \pm 7,78$ & $31,72 \pm 6,65$ \\
\hline Hemoglobina (g/dL) & $11,34 \pm 1,61$ & $11,83 \pm 1,49$ & $12,41 \pm 4,22$ & $11,90 \pm 1,83$ \\
\hline Eritrócitos totais $\left(\mathrm{x} 10^{6} / \mathrm{uL}\right)$ & $10,78 \pm 1,56$ & $12,44 \pm 2,68$ & $11,79 \pm 3,70$ & $10,50 \pm 3,16$ \\
\hline Leucócitos totais (/uL) & $8531 \pm 2671$ & $7364 \pm 1817$ & $7799 \pm 2031$ & $7773 \pm 2575$ \\
\hline Neutrófilos em bastão (/uL) & 0 & 0 & $0,07 \pm 0,26$ & 0 \\
\hline Neutrófilos segmentados (/uL) & $3333 \pm 1578$ & $3052 \pm 1564$ & $2864 \pm 1223$ & $2640 \pm 1045$ \\
\hline Eosinófilos (/uL) & $342,7 \pm 266,8$ & $333,6 \pm 152$ & $195,9 \pm 225,3$ & $345,4 \pm 268,4$ \\
\hline Basófilos (/uL) & $29,30 \pm 49,6$ & $47,21 \pm 68,4$ & $35,71 \pm 44,2$ & $34,9 \pm 52,8$ \\
\hline Monócitos (/uL) & $254,9 \pm 139,4$ & $172,9 \pm 138$ & $226,3 \pm 150,9$ & $261,4 \pm 185,8$ \\
\hline Linfócitos (/uL) & $4571 \pm 1583,7$ & $3758,7 \pm 1080,4$ & $4470,2 \pm 1812$ & $4273 \pm 1745,4$ \\
\hline
\end{tabular}

Letras diferentes na mesma linha indicam diferença significativa $(\mathrm{P}<0,05)$

correspondem aos momentos de maior exigência metabólica. Os valores de glicose, fructosamina e betahidroxibutirato sugerem que pode existir um risco de apresentação de cetose da gestação nessas ovelhas. Os parâmetros hematológicos mostram aumento dos neutrófilos segmentados aos 120 dias de gestação. A contagem de células somáticas encontrada reflete uma boa condição sanitária nos rebanhos analisados.

\section{FONTESDEAQUISIÇÃO}

${ }^{a}$ Labtest, Brasil.

bandox, Reino Unido.

'Bentley 2000, Bentley Instruments, EUA.

${ }^{\mathrm{d} S}$ Somacount 300, Bentley Instruments, EUA.

\section{REFERÊNCIAS}

ALVARENGA, B. A importância da composição do leite como matéria-prima. Escola Superior Agrária de Beja. Capturado em 22 jan. 2002. Online. Disponível na Internet: http://www.esabobeja.pt/adctalimentos/feira-serpa/alvarengab.ppt.

ALTHAUS, R.L. et al. Perfiles metabólicos en ovejas lactantes Corriedale: variación durante la lactancia. Revista Argentina de Producción Animal, v.15, p.1055-1058, 1995.
ANOSA, V.O.; OGBOGU, D.A. The effect of parturition on the blood picture of sheep. Veterinary Science, v.26, p.380382, 1979.

ASSENAT, L. Composición e propiedades. In: LUQUET, F.M. Leche y productos lácteos: vaca-oveja-cabra. Zaragoza: Acribia, 1991. p.277-313.

BARILLET, F. et al. The French Lacaune dairy sheep breed: use in France and abroad in the last 40 years. Livestock Production Science, v.71, p.17-29, 2001.

BENCINI, R.; PULINA, G. The quality of sheep milk: a review. Wool Technology and Sheep Breeding, v.45, p.182-220, 1997.

FORTAGNE, M.; SCHAFER, M. Hematologic parameters of Probstheidaer pigmy goats in relation to pregnancy and lactation. Archivos Exp. Veterinary Medicine, v.43, p.223-230, 1989.

FREDEEN, A.H. Considerations in the milk nutritional modification of milk composition. Animal Feed Science Technology, v.59, p.185-187, 1996.

GONZÁLEZ, C.; VIZCAYA, R. Producción de leche ovina. Argentina: Unicornio Centro Editor, 1993, 166p.

GONZÁLEZ, F.H.D. Uso do perfil metabólico para determinar o status nutricional em gado de corte. In: GONZÁLEZ, F.H.D. et al. (eds). Perfil metabólico em ruminantes: seu uso 
em nutrição e doenças nutricionais. Porto Alegre: UFRGS, 2000. p.63-74.

GONZALO, C. et al. Factors influencing variation of test day milk yield, somatic cell count, fat and protein in dairy sheep. Journal Dairy Science, v.77, p.1537-1542, 1994.

JAIN, N.C. Essentials of veterinary hematology. Philadelphia: Lea \& Febiger, 1993. 417p.

JELINEK, P. et al. Dynamics of basic hematologic values in ewes during the course of a year. Veterinary Medicine, v.31,p.359-370, 1986.

KANEKO, J.J. et al. Clinical biochemistry of domestic animals. 5.ed. San Diego: Academic, 1997. 932p.

KRAJNICAKOVA, M. et al. Dynamic changes in hematologic parameters in the blood of sheep during estrus synchronization and in the subsequent early pregnancy. Veterinary Medicine, v.40, p.177-180, 1995.

KREMER, R. et al. Machine milk yield and composition of non-dairy Corriedale sheep in Uruguai. Small Ruminant Research, v.19, p.9-14, 1996.

LUQUET, F.M. La leche: de la mama a la lechería. Zaragoza: Acribia, 1991. 195p.

PAAPE, M.J. et al. Contagem de células somáticas no leite de pequenos ruminantes. Journal of Dairy Science, v.84, p.236244, 2001.
PEETERS, R. et al. Milk yield and milk composition of Flemish Milksheep, Suffolk and Texel ewes and their crossbreds. Small Ruminant Research, v.7, p.279-288, 1992.

RIBEIRO, L.A.O. et al. Perfil metabólico de ovelhas Border Leicester x Texel durante a gestação e a lactação. Revista Portuguesa de Ciências Veterinárias, v.99, p.155-159, 2004.

RIBEIRO, L.A.O. Perdas reprodutivas em ovinos no Rio Grande do Sul determinadas pelas condições nutricionais e de manejo no encarneiramento e na gestação. 2002. 106f. Tese (Doutorado em Ciências Veterinárias) - Universidade Federal do Rio Grande do Sul.

RUSSEL, A.J.F. Nutrition of pregnant ewe. In: BODEN, D. (Ed). Sheep and goat practice. London: Baillière Trindall, 1991. p.29-39.

SCHOLZ, W. Elaboración de quesos de oveja y de cabra. Zaragoza: Acribia, 1997. 145p.

TADICH, N. et al. Efecto de un programa de salud en ovinos sobre la condición corporal y los valores sanguíneos de betahidroxibutirato, hematocrito y urea. Archivos de Medicina Veterinaria, v.26, p.43-50, 1994.

WITTWER, F. Marcadores bioquímicos no controle de problemas metabólicos nutricionais em gado de leite. In: GONZÁleZ, F.H.D. et al. (eds). Perfil metabólico em ruminantes: seu uso em nutrição e doenças nutricionais. Porto Alegre: UFRGS, 2000. p.53-62. 